\title{
Candidate chemosensory genes identified in Colaphellus bowringi by antennal transcriptome analysis
}

\author{
Xiao-Ming Li ${ }^{1}$, Xiu-Yun Zhu' ${ }^{1}$, Zhi-Qiang Wang ${ }^{1}$, Yi Wang ${ }^{1}$, Peng He${ }^{2}$, Geng Chen ${ }^{1}$, Liang Sun ${ }^{3}$, Dao-Gui Deng ${ }^{1}$ \\ and Ya-Nan Zhang ${ }^{1 *}$
}

\begin{abstract}
Background: Since chemosensory genes play key roles in insect behaviour, they can potentially be used as new targets for pest control. The cabbage beetle, Colaphellus bowringi, is a serious insect pest of cruciferous vegetables in China and other Asian countries. However, a systematic identification of the chemosensory genes expressed in the antennae has not been reported.

Results: We assembled the antennal transcriptome of C. bowringi by using Illumina sequencing technology and identified 104 candidate chemosensory genes by analyzing transcriptomic data, which included transcripts encoding 26 odorant-binding proteins (OBPs), 12 chemosensory proteins (CSPs), four sensory neuron membrane proteins (SNMPs), 43 odorant receptors (ORs), nine ionotropic receptors (IRs), and ten gustatory receptors (GRs). The data obtained are similar to those found in other coleopteran species, suggesting that our approach successfully identified the chemosensory genes of $C$. bowringi. The expression patterns of 43 OR genes, some of which were predominately found in the antenna or associated with sex-biased expression, were analyzed using quantitative real time RT-PCR (qPCR).
\end{abstract}

Conclusions: Our study revealed that a large number of chemosensory genes are expressed in C. bowringi. These candidate chemosensory genes and their expression profiles in various tissues provide further information on understanding their function in C. bowringi as well as other insects, and identifying potential targets to disrupt the odorant system in C. bowringi so that new methods for pest management can be developed.

Keywords: Transcriptome analysis, Chemosensory gene, Antenna, Tissue expression, Cabbage beetle

\section{Background}

The olfactory system plays a key role in various insect behaviours, such as those related to locating suitable hosts, avoiding predators, identifying oviposition sites, and finding sexual partners [1]. The antennae are crucial olfactory organs in this system, and many studies have demonstrated that the system generally involves two main steps. Firstly, odorants penetrate the sensillar lymph through pores, wherein they are recognised and bound by odorant-binding proteins (OBPs) [2-4] or chemosensory proteins (CSPs) [5, 6]. Secondly, it was speculated that the OBPs or CSPs were the transporters

\footnotetext{
* Correspondence: ynzhang_insect@163.com

'College of Life Sciences, Huaibei Normal University, Huaibei 235000, China
}

Full list of author information is available at the end of the article that transferred odorants through the sensillar lymph to a family of integral membrane protein, the olfactory receptors (ORs), located on the dendrites of olfactory receptor neurons (ORNs) [7-10]. Additionally, sensory neuron membrane proteins (SNMPs) [11, 12] and ionotropic receptors (IRs) [2, 13-15] have also been proposed to play a role in insect olfaction.

To thoroughly explore the mechanisms of insect olfaction, tissue or sex expression profiling as well as functional analyses of candidate chemosensory genes are the primary important steps that should be performed. Compared with initial techniques such as gene cloning with degenerate primers and Rapid Amplification of cDNA Ends (RACE) [16-19], RNA-seq is considered to be a timesaving, cost effective, and highly efficient

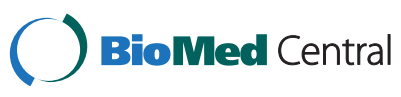

(C) 2015 Li et al. Open Access This article is distributed under the terms of the Creative Commons Attribution 4.0 International License (http://creativecommons.org/licenses/by/4.0/), which permits unrestricted use, distribution, and reproduction in any medium, provided you give appropriate credit to the original author(s) and the source, provide a link to the Creative Commons license, and indicate if changes were made. The Creative Commons Public Domain Dedication waiver (http:// creativecommons.org/publicdomain/zero/1.0/) applies to the data made available in this article, unless otherwise stated. 
method. Therefore, large-scale studies identifying chemosensory genes have been undertaken with distinct insects whose genomes have not been sequenced in recent years, such as Ips typographus (european spruce bark beetle) [20], Dendroctonus ponderosae (mountain pine beetle) [20], Dendroctonus valens (red turpentine beetle) [21], Anomala corpulenta (metallic green beetle) [22], Sesamia inferens (purple stem borer) [23], and Helicoverpa armigera (cotton bollworm) [24].

To date, many chemosensory genes have been identified from insects of almost every insect order. However, their exact functions are largely unknown, as these genes were identified based on sequence similarity to previously reported genes. Examination of gene expression profiles, particularly the tissue or sex distribution, and phylogenetic analyses could potentially provide important information concerning the function of chemosensory genes [25-30].

The cabbage beetle, Colaphellus bowringi Baly (Coleoptera: Chrysomelidae), is a serious insect pest and widely distributed in China as well as some other Asian countries. It primarily feeds on the developing leaves of cruciferous vegetables such as Raphanus sativus, Brassica chinensis, B. pekinensis and B. campestris, and aestivates and hibernates in the soil during the adult stage $[31,32]$. There are two distinct infestation peaks annually: one in spring with a single generation and a second in autumn involving three generations. Both sexes copulate an average of five times per day [33-35], and 15dayold partners have significantly greater mating success in mate choice than other developmental stages [36, 37]. However, highly effective sex attractants and pesticides to control the pest are not available [38, 39].

In this study, we performed a transcriptome analysis of adult antennae of $C$. bowringi, and identified 104 candidate chemosensory genes comprising 26 OBPs, 12 CSPs, 4 SNMPs, 43 ORs, 9 IRs, and 10 GRs. Furthermore, we conducted a comprehensive and comparative phylogenetic analysis and examined OR gene transcription patterns using quantitative real-time RT-PCR (qPCR). The results clearly revealed a unique feature of sex-biased expression of some ORs, and ultimately allowed us to identify potential targets to disrupt odorant perception in C. bowringi that could lead to new pest management techniques.

\section{Results}

Transcriptome sequencing and sequence assembly

We carried out next-generation sequencing on a cDNA library constructed from the adult antennae of C. bowringi using the Illumina HiSeq ${ }^{\mathrm{Tm}} 2500$ platform. The transcriptome sequence consisted of approximately 50 million clean reads $(5.0 \mathrm{~Gb})$. After clustering and redundancy filtering, we identified 41,761 unigenes with an N50 length of 1510 bp (Table 1).
Table 1 Summary of C. bowringi transcriptome assembly

\begin{tabular}{ll}
\hline Statistics project & Number \\
\hline Total clean reads & $50,737,524$ \\
GC percentage & $41.13 \%$ \\
Q20 percentage & $96.84 \%$ \\
Total unigene nucleotides & $33,080,006$ \\
Total unigene & 41,761 \\
N50 of unigenes (nt) & 1510 \\
Min length of unigenes (nt) & 201 \\
Median length of unigenes (nt) & 379 \\
Max length of unigenes (nt) & 21,193 \\
Unigenes with homolog in NR & 18,903 \\
\hline
\end{tabular}

We called these 41,761sequences unigenses, although each might not necessarily represent a unique gene. Of the 41,761 unigenes, those with a sequence length greater than $500 \mathrm{bp}$ accounted for $39.55 \%$ of the transcriptome assembly (Additional file 1: Figure S1).

\section{Homology analysis and Gene Ontology (GO) annotation}

Among the 41,761 unigenes, 18,903 were matched by a Blastx similarity of the entries in the NCBI nonredundant (nr) protein database, with a cut-off E-value of $10^{-5}$. The highest match percentage $(54.60 \%)$ was to Tribolium castaneum (red flour beetle) sequences followed by Dendroctonus ponderosae (16.70 \%), Acyrthosiphon pisum (pea aphid) (2.50\%), Diaphorina citri (asian citrus psyllid) (1.90\%) and Bombyx mori (silkworm) (1.30 \%) (Additional file 2: Figure S2).

Gene Ontology (GO) annotation was used to classify transcripts into functional groups according to the GO category. Of the 41,761 unigenes, 14,147 (33.87\%) could be annotated based on sequence similarity. In the molecular function category, the genes expressed in the antenna were mostly associated with binding, catalytic, and transporter activities. In the biological process category, cellular, metabolic, and single-organism processes were the most represented. In the cellular component category, cell, cell part, and organelle were the most abundant groups (Additional file 3: Figure S3).

\section{Identification of candidate chemosensory genes}

By similarity analysis, a total of 104 transcripts belonging to gene families putatively involved in insect chemoreception were identified, including OBPs (26 transcripts), CSPs (12 transcripts), SNMPs (four transcripts), ORs (43 transcripts), IRs (9 transcripts) and GRs (10 transcripts) (Tables 2 and 3). Compared with insects where the chemosensory genes had been identified by analyzing either the genome or transcriptome, the number of candidate chemosensory genes identified here in 
Table 2 The Blastx Match of C. bowringi candidate OBPs, CSPs and SNMPs genes

\begin{tabular}{|c|c|c|c|c|c|c|c|c|c|c|}
\hline \multirow{2}{*}{$\begin{array}{l}\text { Gene } \\
\text { Name }\end{array}$} & \multirow{2}{*}{$\begin{array}{l}\text { Acc. } \\
\text { No. }\end{array}$} & \multirow{2}{*}{$\begin{array}{l}\text { ORF } \\
\text { (aa) }\end{array}$} & \multirow{2}{*}{$\begin{array}{l}\text { Signal } \\
\text { Peptide }\end{array}$} & \multirow{2}{*}{$\begin{array}{l}\text { Complete } \\
\text { ORF }\end{array}$} & \multicolumn{5}{|l|}{ Best Blastx Match } & \multirow[b]{2}{*}{ Group } \\
\hline & & & & & Name & Acc. No. & Species & E value & Identity (\%) & \\
\hline \multicolumn{11}{|c|}{ Odorant Binding Protein (OBP) } \\
\hline OBP1 & KT381483 & 142 & $1-19$ & Y & odorant-binding protein 1 & AHA33382.1 & Batocera horsfieldi & $2.00 \mathrm{E}-61$ & 65 & Classic \\
\hline OBP2 & KT381484 & 142 & $1-21$ & Y & odorant binding protein 23 & EFA10803.1 & Tribolium castaneum & $1.00 \mathrm{E}-43$ & 59 & Classic \\
\hline OBP3 & KT381485 & 89 & $\mathrm{~N}$ & $\mathrm{~N}$ & odorant-binding protein 5 & АНА39270.1 & Monochamus alternatus & $1.00 \mathrm{E}-20$ & 47 & - \\
\hline OBP4 & KT381486 & 113 & $\mathrm{~N}$ & $\mathrm{~N}$ & odorant-binding protein 26 & AGI05179.1 & Dendroctonus ponderosae & 5.00E-19 & 35 & - \\
\hline OBP5 & KT381487 & 131 & $1-18$ & Y & odorant-binding protein 5 & AHA39270.1 & Monochamus alternatus & $5.00 \mathrm{E}-10$ & 35 & Minus-C \\
\hline OBP6 & KT381488 & 133 & $1-16$ & Y & odorant-binding protein 2 & АНА39267.1 & Monochamus alternatus & $1.00 \mathrm{E}-37$ & 58 & Minus-C \\
\hline OBP7 & KT381489 & 136 & $1-21$ & Y & $\begin{array}{l}\text { pheromone binding protein } \\
\text { PBP1 }\end{array}$ & AIV43008.1 & Batocera horsfieldi & 4.00E-48 & 63 & Classic \\
\hline OBP8 & KT381490 & 134 & $1-24$ & Y & odorant-binding protein 3 & AHA33381.1 & Batocera horsfieldi & $1.00 \mathrm{E}-07$ & 35 & Classic \\
\hline OBP9 & KT381491 & 151 & $1-19$ & Y & odorant-binding protein 1 & AJM71475.1 & Tenebrio molitor & $1.00 \mathrm{E}-27$ & 37 & Classic \\
\hline OBP10 & KT381492 & 134 & $1-27$ & Y & odorant binding protein 05 & EFA05677.1 & Tribolium castaneum & $2.00 \mathrm{E}-06$ & 37 & Classic \\
\hline OBP11 & KT381493 & 140 & $1-18$ & Y & odorant binding protein 1 & ABR53888.1 & Monochamus alternatus & $2.00 \mathrm{E}-10$ & 33 & Minus-C \\
\hline OBP12 & KT381494 & 248 & $1-18$ & Y & odorant binding protein 2 & AKK25130.1 & Dendroctonus valens & $1.00 \mathrm{E}-31$ & 62 & Classic \\
\hline OBP13 & KT381495 & 133 & $1-18$ & Y & odorant binding protein & AHE13799.1 & Lissorhoptrus oryzophilus & $1.00 \mathrm{E}-22$ & 37 & Minus-C \\
\hline OBP14 & KT381496 & 123 & $1-23$ & Y & odorant-binding protein 16 & AGI05186.1 & Dendroctonus ponderosae & $3.00 \mathrm{E}-06$ & 29 & Classic \\
\hline OBP15 & KT381497 & 140 & $1-19$ & Y & $\begin{array}{l}\text { minus- } C \text { odorant binding } \\
\text { protein } 3\end{array}$ & ADD82416.1 & Batocera horsfieldi & $8.00 \mathrm{E}-14$ & 40 & Minus-C \\
\hline OBP16 & KT381498 & 141 & $1-18$ & Y & $\begin{array}{l}\text { minus- } C \text { odorant binding } \\
\text { protein } 2\end{array}$ & ADD70031.1 & Batocera horsfieldi & $3.00 \mathrm{E}-18$ & 32 & Minus-C \\
\hline OBP17 & KT381499 & 136 & $1-18$ & Y & odorant-binding protein 2 & AHA33380.1 & Batocera horsfieldi & 4.00E-48 & 57 & Classic \\
\hline OBP18 & KT381500 & 179 & $1-22$ & Y & odorant-binding protein 28 & AHF71059.1 & Lygus lineolaris & $2.00 \mathrm{E}-50$ & 50 & Plus-C \\
\hline OBP19 & KT381501 & 130 & $1-22$ & Y & odorant-binding protein 5 & AHA39270.1 & Monochamus alternatus & $8.00 \mathrm{E}-14$ & 34 & Minus-C \\
\hline OBP20 & KT381502 & 130 & $1-15$ & Y & odorant binding protein 4 & AKK25132.1 & Dendroctonus valens & $2.00 \mathrm{E}-34$ & 44 & Minus-C \\
\hline OBP21 & KT381503 & 142 & $1-20$ & Y & odorant binding protein & AHE13800.1 & Lissorhoptrus oryzophilus & $1.00 \mathrm{E}-07$ & 25 & Minus-C \\
\hline OBP22 & KT381504 & 132 & $1-16$ & Y & odorant binding protein 10 & AKK25136.1 & Dendroctonus valens & 4.00E-13 & 30 & Minus-C \\
\hline OBP23 & KT381505 & 130 & $1-19$ & Y & odorant binding protein C03 & EFA07546.1 & Tribolium castaneum & $9.00 \mathrm{E}-18$ & 37 & Minus- $C$ \\
\hline OBP24 & KT381506 & 103 & $\mathrm{~N}$ & $\mathrm{~N}$ & $\begin{array}{l}\text { minus-C odorant binding } \\
\text { protein } 4\end{array}$ & ADD82417.1 & Batocera horsfieldi & 7.00E-12 & 36 & - \\
\hline OBP25 & KT381507 & 248 & $1-21$ & Y & odorant-binding protein 2 & AGl05158.1 & Dendroctonus ponderosae & $2.00 \mathrm{E}-51$ & 41 & Plus-C \\
\hline OBP26 & KT381508 & 150 & $1-16$ & Y & odorant binding protein 12 & EFA02857.1 & Tribolium castaneum & 1.00E-22 & 36 & Classic \\
\hline
\end{tabular}


Table 2 The Blastx Match of C. bowringi candidate OBPs, CSPs and SNMPs genes (Continued)

\begin{tabular}{|c|c|c|c|c|c|c|c|c|c|}
\hline CSP1 & KT381509 & 126 & $1-18$ & Y & chemosensory protein 12 & NP_001039280.1 & Tribolium castaneum & $1.00 \mathrm{E}-40$ & 56 \\
\hline CSP2 & KT381510 & 138 & $1-19$ & Y & $\begin{array}{l}\text { chemosensory protein } 11 \\
\text { precursor }\end{array}$ & NP_001039279.1 & Tribolium castaneum & $2.00 E-31$ & 52 \\
\hline CSP3 & KT381511 & 130 & $1-19$ & Y & chemosensory protein 6 & AGI05162.1 & Dendroctonus ponderosae & $4.00 E-34$ & 55 \\
\hline CSP4 & KT381512 & 124 & $1-18$ & Y & CSP11 & AKI84394.1 & Holotrichia parallela & $1.00 E-37$ & 53 \\
\hline CSP5 & KT381513 & 126 & $1-17$ & Y & chemosensory protein 8 & AHE13803.1 & Lissorhoptrus oryzophilus & $7.00 \mathrm{E}-45$ & 80 \\
\hline CSP6 & KT381514 & 123 & $1-19$ & Y & chemosensory protein 2 & AGI05172.1 & Dendroctonus ponderosae & 7.00E-36 & 45 \\
\hline CSP7 & KT381515 & 125 & $1-18$ & Y & $\begin{array}{l}\text { chemosensory protein } 7 \\
\text { precursor }\end{array}$ & NP_001039289.1 & Tribolium castaneum & $1.00 \mathrm{E}-54$ & 69 \\
\hline CSP8 & KT381516 & 97 & $1-19$ & $\mathrm{~N}$ & chemosensory protein CSP3 & AJO62209.1 & Tenebrio molitor & $7.00 \mathrm{E}-33$ & 59 \\
\hline CSP9 & KT381517 & 148 & $\mathrm{~N}$ & Y & chemosensory protein CSP7 & AJ062213.1 & Tenebrio molitor & $9.00 \mathrm{E}-31$ & 46 \\
\hline CSP10 & KT381518 & 138 & $1-16$ & Y & chemosensory protein 8 & AHE13803.1 & Lissorhoptrus oryzophilus & $3.00 \mathrm{E}-30$ & 45 \\
\hline CSP11 & KT381519 & 113 & $\mathrm{~N}$ & Y & $\begin{array}{l}\text { chemosensory protein } 1 \\
\text { isoform } \mathrm{X} 1\end{array}$ & XP_008200934.1 & Tribolium castaneum & $1.00 \mathrm{E}-42$ & 69 \\
\hline CSP12 & KT381520 & 162 & $\mathrm{~N}$ & Y & chemosensory protein & AFI45003.1 & Dendroctonus ponderosae & $9.00 \mathrm{E}-65$ & 72 \\
\hline \multicolumn{10}{|c|}{ Sensory Neuron Membrane Protein (SNMP) } \\
\hline SNMP1a & KT381536 & 514 & & Y & SNMP-1 & AJ062245.1 & Tenebrio molitor & $0.00 E+00$ & 59 \\
\hline SNMP1b & KT381537 & 534 & & Y & sensory neuron membrane protein & AFI45066.1 & Dendroctonus ponderosae & $0.00 E+00$ & 52 \\
\hline SNMP2 & KT381538 & 522 & & Y & SNMP-2 & AJ062246.1 & Tenebrio molitor & $9.00 \mathrm{E}-119$ & 42 \\
\hline SNMP3 & KT381539 & 520 & & Y & $\begin{array}{l}\text { sensory neuron membrane } \\
\text { protein 2-like }\end{array}$ & XP_008198962.1 & Tribolium castaneum & $3.00 \mathrm{E}-162$ & 46 \\
\hline
\end{tabular}


Table 3 The Blastx Match of C. bowringi candidate ORs, IRs and GR genes

\begin{tabular}{|c|c|c|c|c|c|c|c|c|c|}
\hline \multirow{2}{*}{$\begin{array}{l}\text { Gene } \\
\text { Name }\end{array}$} & \multirow{2}{*}{$\begin{array}{l}\text { Acc. } \\
\text { No. }\end{array}$} & \multirow{2}{*}{$\begin{array}{l}\text { ORF } \\
\text { (aa) }\end{array}$} & \multirow{2}{*}{$\begin{array}{l}\text { Signal } \\
\text { Peptide }\end{array}$} & \multirow{2}{*}{$\begin{array}{l}\text { Complete } \\
\text { ORF }\end{array}$} & \multicolumn{5}{|l|}{ Best Blastx Match } \\
\hline & & & & & Name & Acc. No. & Species & E value & Identity (\%) \\
\hline \multicolumn{10}{|c|}{ Odorant Receptor (OR) } \\
\hline OR1 & KT381540 & 344 & 4 & $\mathrm{~N}$ & odorant receptor 127 & EEZ97733.1 & Tribolium castaneum & $1.00 \mathrm{E}-24$ & 26 \\
\hline ORco(OR2) & KT381541 & 479 & 7 & Y & odorant receptor co-receptor & AJF94638.2 & Ambrostoma quadrimpressum & $0.00 E+00$ & 92 \\
\hline OR3 & KT381542 & 330 & 5 & $N$ & odorant receptor 43 & EEZ99411.1 & Tribolium castaneum & $6.00 \mathrm{E}-101$ & 44 \\
\hline OR4 & KT381543 & 378 & 6 & Y & odorant receptor 14 & AKC58549.1 & Anomala corpulenta & $3.00 E-44$ & 30 \\
\hline OR5 & KT381544 & 254 & 4 & $N$ & odorant receptor 18 & AKC58553.1 & Anomala corpulenta & $1.00 \mathrm{E}-16$ & 28 \\
\hline OR6 & KT381545 & 384 & 7 & Y & odorant receptor 89 & EFA10702.1 & Tribolium castaneum & $3.00 E-43$ & 32 \\
\hline OR7 & KT381546 & 318 & 4 & N & olfactory receptor OR16 & AJ062235.1 & Tenebrio molitor & $2.00 E-47$ & 32 \\
\hline OR8 & KT381547 & 174 & 3 & N & odorant receptor 44 & EEZ99412.1 & Tribolium castaneum & $3.00 E-43$ & 40 \\
\hline OR9 & KT381548 & 336 & 5 & N & odorant receptor 59 & EEZ99171.1 & Tribolium castaneum & 1.00E-91 & 44 \\
\hline OR10 & KT381549 & 363 & 5 & Y & odorant receptor 14 & AKC58549.1 & Anomala corpulenta & $1.00 \mathrm{E}-41$ & 27 \\
\hline OR11 & KT381550 & 336 & 5 & N & odorant receptor 64 & EFA10800.1 & Tribolium castaneum & $5.00 \mathrm{E}-146$ & 56 \\
\hline OR12 & KT381551 & 156 & 2 & $N$ & odorant receptor 47 & EFA02940.1 & Tribolium castaneum & $9.00 \mathrm{E}-24$ & 36 \\
\hline OR13 & KT381552 & 420 & 8 & Y & odorant receptor 14 & AKC58549.1 & Anomala corpulenta & $1.00 E-33$ & 27 \\
\hline OR14 & KT381553 & 356 & 4 & N & odorant receptor 58 & EEZ99414.1 & Tribolium castaneum & $1.00 \mathrm{E}-49$ & 33 \\
\hline OR15 & KT381554 & 389 & 7 & Y & odorant receptor 3 & EFA01310.1 & Tribolium castaneum & $1.00 \mathrm{E}-66$ & 36 \\
\hline OR16 & KT381555 & 196 & 0 & N & odorant receptor 128 & EFA02867.1 & Tribolium castaneum & $9.00 \mathrm{E}-10$ & 21 \\
\hline OR17 & KT381556 & 387 & 7 & Y & odorant receptor 80 & EFA10776.1 & Tribolium castaneum & $3.00 E-55$ & 30 \\
\hline OR18 & KT381557 & 174 & 0 & N & odorant receptor 49b-like & XP_001812261.1 & Tribolium castaneum & $4.00 E-18$ & 34 \\
\hline OR19 & KT381558 & 379 & 6 & Y & odorant receptor 89 & EFA10702.1 & Tribolium castaneum & $2.00 E-45$ & 32 \\
\hline OR20 & KT381559 & 248 & 3 & N & odorant receptor 23 & AGl05173.1 & Dendroctonus ponderosae & $3.00 E-12$ & 24 \\
\hline OR21 & KT381560 & 355 & 4 & N & odorant receptor 58 & EEZ99414.1 & Tribolium castaneum & $1.00 \mathrm{E}-48$ & 32 \\
\hline OR22 & KT381561 & 390 & 3 & Y & odorant receptor 89 & EFA10702.1 & Tribolium castaneum & $3.00 E-41$ & 29 \\
\hline OR23 & - & 42 & 0 & N & odorant receptor 82a & XP_966790.1 & Tribolium castaneum & $3.00 E-57$ & 45 \\
\hline OR24 & KT381562 & 395 & 4 & Y & odorant receptor 89 & EFA10702.1 & Tribolium castaneum & $2.00 E-51$ & 29 \\
\hline OR25 & - & 58 & 0 & N & odorant receptor 35 & EEZ99408.1 & Tribolium castaneum & $2.00 \mathrm{E}-21$ & 73 \\
\hline OR26 & KT381563 & 380 & 6 & Y & odorant receptor 41 & EEZ99227.1 & Tribolium castaneum & $2.00 E-46$ & 29 \\
\hline OR27 & KT381564 & 398 & 6 & Y & odorant receptor 167 & EFA02801.1 & Tribolium castaneum & $9.00 \mathrm{E}-70$ & 35 \\
\hline OR28 & KT381565 & 368 & 4 & Y & odorant receptor 120 & EEZ99330.1 & Tribolium castaneum & $3.00 E-14$ & 24 \\
\hline OR29 & KT381566 & 250 & 3 & N & odorant receptor 14 & AKC58549.1 & Anomala corpulenta & $7.00 E-29$ & 29 \\
\hline OR30 & KT381567 & 194 & 4 & N & odorant receptor 37 & EEZ99229.1 & Tribolium castaneum & $3.00 E-29$ & 30 \\
\hline OR31 & KT381568 & 418 & 6 & Y & odorant receptor 14 & AKC58549.1 & Anomala corpulenta & $1.00 \mathrm{E}-36$ & 27 \\
\hline OR32 & КT381569 & 393 & 6 & Y & odorant receptor 94a-like & XP_011629601.1 & Pogonomyrmex barbatus & $5.00 \mathrm{E}-13$ & 27 \\
\hline
\end{tabular}


Table 3 The Blastx Match of C. bowringi candidate ORs, IRs and GR genes (Continued)

\begin{tabular}{|c|c|c|c|c|c|c|c|c|c|}
\hline OR33 & KT381570 & 185 & 2 & N & olfactory receptor OR10 & AJ062229.1 & Tenebrio molitor & $3.00 \mathrm{E}-51$ & 37 \\
\hline OR34 & KT381571 & 436 & 5 & Y & odorant receptor Or1-like & XP_008560066.1 & Microplitis demolitor & $3.00 \mathrm{E}-16$ & 27 \\
\hline OR35 & KT381572 & 388 & 4 & Y & odorant receptor 92 & EFA02873.1 & Tribolium castaneum & $6.00 \mathrm{E}-49$ & 30 \\
\hline OR36 & KT381573 & 383 & 7 & Y & odorant receptor 14 & AKC58549.1 & Anomala corpulenta & $7.00 \mathrm{E}-58$ & 32 \\
\hline OR37 & KT381574 & 371 & 4 & Y & odorant receptor 123 & EEZ99420.1 & Tribolium castaneum & 2.00E-14 & 24 \\
\hline OR38 & KT381575 & 271 & 2 & N & odorant receptor 37 & EEZ99229.1 & Tribolium castaneum & $2.00 \mathrm{E}-82$ & 47 \\
\hline OR39 & KT381576 & 121 & 2 & N & olfactory receptor OR60 & AJE25900.1 & Planotortrix excessana & $6.00 \mathrm{E}-07$ & 39 \\
\hline OR40 & KT381577 & 369 & 6 & Y & putative olfactory receptor 10 & BAR43452.1 & Ostrinia furnacalis & $1.00 \mathrm{E}-19$ & 23 \\
\hline OR41 & KT884514 & 79 & 0 & $\mathrm{~N}$ & odorant receptor 184 & EFA01394.1 & Tribolium castaneum & $1.00 \mathrm{E}-05$ & 33 \\
\hline OR42 & KT884515 & 83 & 0 & $\mathrm{~N}$ & olfactory receptor 17 & CAM84015.1 & Tribolium castaneum & $3.00 \mathrm{E}-04$ & 27 \\
\hline OR43 & KT884516 & 73 & 0 & N & odorant receptor 3 & EFA01310.1 & Tribolium castaneum & $1.00 \mathrm{E}-04$ & 38 \\
\hline \multicolumn{10}{|c|}{ Ionotropic Receptor (IR) } \\
\hline IR6 & KT381529 & 920 & 3 & Y & chemosensory ionotropic receptor IR6 & AJ062244.1 & Tenebrio molitor & $0.00 E+00$ & 80 \\
\hline IR21a & KT381530 & 158 & 1 & $\mathrm{~N}$ & chemosensory ionotropic receptor $21 \mathrm{a}$ & AKC58586.1 & Anomala corpulenta & $1.00 \mathrm{E}-82$ & 58 \\
\hline IR75q & KT381531 & 483 & 3 & $\mathrm{~N}$ & chemosensory ionotropic receptor $75 q$ & AKC58589.1 & Anomala corpulenta & $3.00 \mathrm{E}-110$ & 46 \\
\hline IR8a & KT381532 & 866 & 3 & Y & ionotropic receptor 8a & AGI05169.1 & Dendroctonus ponderosae & $0.00 E+00$ & 60 \\
\hline IR41a & KT381533 & 347 & 2 & N & chemosensory ionotropic receptor 41 a & AKC58587.1 & Anomala corpulenta & $5.00 \mathrm{E}-65$ & 40 \\
\hline IR5 & KT381534 & 552 & 3 & Y & chemosensory ionotropic receptor IR5 & AJ062243.1 & Tenebrio molitor & 4.00E-180 & 52 \\
\hline IR2 & KT381535 & 607 & 3 & Y & chemosensory ionotropic receptor IR2 & AJ062240.1 & Tenebrio molitor & $0.00 E+00$ & 60 \\
\hline IR64a & KT884510 & 213 & 1 & N & ionotropic receptor & BAR64801.1 & Ostrinia furnacalis & $6.00 \mathrm{E}-57$ & 38 \\
\hline IR68a & KT884511 & 95 & 0 & N & ionotropic receptor & BAR64802.1 & Ostrinia furnacalis & $3.00 \mathrm{E}-44$ & 66 \\
\hline \multicolumn{10}{|c|}{ Gustatory Receptor (GR) } \\
\hline GR1 & KT381521 & 134 & 0 & $\mathrm{~N}$ & gustatory receptor 99 & EFA02933.1 & Tribolium castaneum & $5.00 \mathrm{E}-06$ & 35 \\
\hline GR2 & KT381522 & 287 & 5 & N & gustatory receptor & ABY40623.1 & Tribolium castaneum & $9.00 \mathrm{E}-71$ & 52 \\
\hline GR3 & KT381523 & 120 & 2 & N & gustatory receptor 6 & EFA04712.1 & Tribolium castaneum & $1.00 \mathrm{E}-30$ & 48 \\
\hline GR4 & KT381524 & 216 & 5 & N & gustatory receptor & ABY40595.1 & Tribolium castaneum & 2.00E-06 & 33 \\
\hline GR5 & KT381525 & 77 & 0 & N & gustatory receptor for sugar taste $43 a-$-like & XP_001813898.1 & Tribolium castaneum & $3.00 \mathrm{E}-17$ & 49 \\
\hline GR6 & KT381526 & 183 & 3 & N & putative gustatory receptor $28 \mathrm{~b}$ & XP_001813096.2 & Tribolium castaneum & $5.00 \mathrm{E}-08$ & 38 \\
\hline GR7 & KT381527 & 113 & 1 & N & gustatory receptor candidate 10 & CAL23143.2 & Tribolium castaneum & $2.00 \mathrm{E}-59$ & 82 \\
\hline GR8 & KT381528 & 118 & 2 & N & gustatory receptor 2 isoform $X_{1}$ & XP_008191523.1 & Tribolium castaneum & $2.00 \mathrm{E}-68$ & 82 \\
\hline GR9 & KT884512 & 81 & 1 & N & gustatory receptor 102 & EFA02935.1 & Tribolium castaneum & $2.00 \mathrm{E}-04$ & 29 \\
\hline GR10 & KT884513 & 79 & 1 & N & gustatory receptor & ABY40593.1 & Tribolium castaneum & 4.00E-04 & 33 \\
\hline
\end{tabular}


C. bowringi was similar to those in D. ponderosae (111) and more than I. typographus (80), but less than in $T$. castaneum (642) (Fig. 1).

\section{OBPs}

We identified 26 different transcripts encoding candidate OBPs in C. bowringi, which is less than that in $D$. ponderosae (31), but more than that in I. typographus (15), A. corpulenta (15), and D. valens (21). The results of the sequence analysis revealed 23 transcripts with a full-length open reading frame (ORF) with predicted signal peptide sequences, and CbowOBP3, 4, 24 corresponded to a partial sequence that encoded amino acids from 89 to 113. Except for CbowOBP18, the other 25 CbowOBPs identified were similar to known coleopteran OBPs (Table 2). Among the 26 CbowOBPs, CbowOBP5 showed the highest expression level $(\mathrm{RPKM}=18323.68)$ (Additional file 4: Table S1)

A phylogenetic tree of the OBPs was constructed using the protein sequences from $C$. bowringi, T. castaneum, D. ponderosae, I. typographus, A. corpulenta, and Drosophila melanogaster (fruit fly) (Fig. 2). As previous reports [4, 40-42] and our results, 23 fulllength CbowOBPs could be divided into three groups: Minus-C OBPs (CbowOBP5, 6, 11, 13, 15, 16, 19, 20, 21, 22 and 23), Plus-C OBPs (CbowOBP18 and 25), and the remainder Classic OBPs.

\section{CSPs}

In total, 12 different transcripts encoding candidate CSPs with four conserved cysteine profiles were obtained in C. bowringi through bioinformatic analysis, which included 11 sequences predicted to be full length and 8 with a signal peptide (Table 2), with CbowCSP3 harbouring the highest expression level (RPKM = 4155.27) (Additional file 4: Table S1). The phylogenetic tree revealed two branches with high bootstrap values: CbowCSP8 with TcasCSP8 and DponCSP11, and finally CbowCSP11 with AgamCSP8, BmorCSP20, and BmorCSP21 (Fig. 3).

\section{SNMPs}

Four SNMP homologs with full-length ORFs were also obtained from the $C$. bowringi transcriptome. This number is consistent with $D$. valens, but is greater than that in other previously studied coleoptera insects (Fig. 1). The Blastx results demonstrated that CbowSNMPs encoding proteins harboured a 42-59\% identity to those of other reported insects (Table 2). The RPKM results showed that CbowSNMPs displayed the highest expression level (RPKM = 90.28) (Additional file 4: Table S1). Based on the phylogenetic analysis, we found that CbowSNMP1a and CbowSNMP1b clustered with the coleoptera SNMP1 group, while CbowSNMP2 and CbowSNMP3 clustered with high support with DponSNMP2 and ItypSNMP2Fix, respectively (Additional file 5: Figure S4).

\section{ORs}

Forty-three different transcripts for candidate ORs were identified based on the antennal transcriptome data for C. bowringi, among which 20 sequences contained a full-length ORF that encoded 363 to 479 amino acids. We identified one OR sequence that shared a high level of identity with the conserved ORco proteins of other insect species and labelled it CbowORco. The aminoacid sequence of CbowORco shared $92 \%$ identity with the co-receptor of Ambrostoma quadriimpressum (leaf beetle) (AJF94638.2). More than $80 \%$ of the CbowORs were highly divergent, and had low levels of identity (21-40 \%) with other reported insect ORs. Based on prediction and comparison with other insect ORs [20, 22], we found full-length CbowORs had 3 to 8 TMD (transmembrane domains) (Table 3 ).

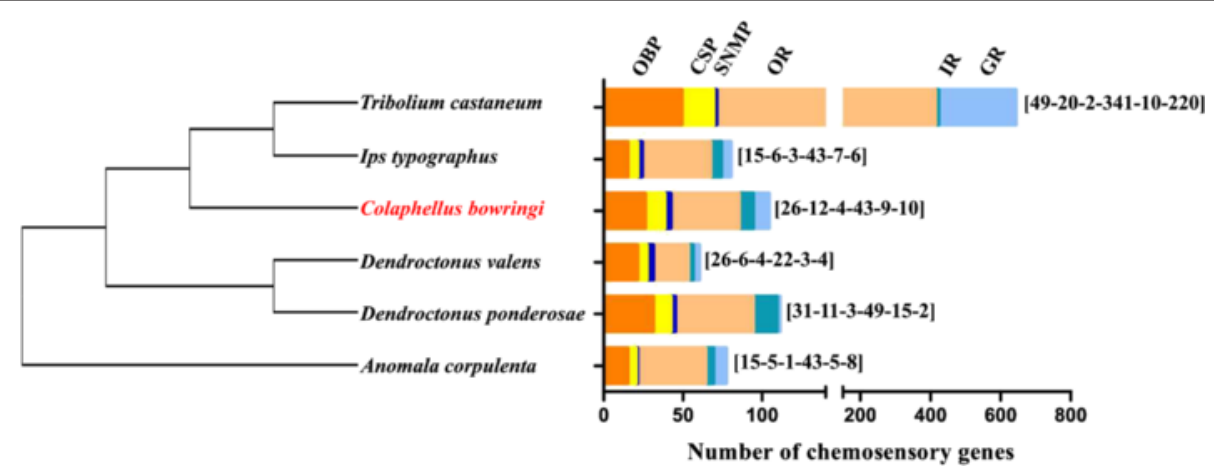

Fig. 1 The number of chemosensory genes in different insect species. The digits by the histogram bars represent number of chemosensory genes in different subfamilies. A phylogenetic tree showing the phylogenetic relationships between these species is illustrated on the left. The data are obtained from the current study for C. bowringi and from the references [9, 10, 12, 15] for Tribolium castaneum, [20] for Ips typographus and Dendroctonus ponderosae, [21] for D. valens and [22] for Anomala corpulenta 


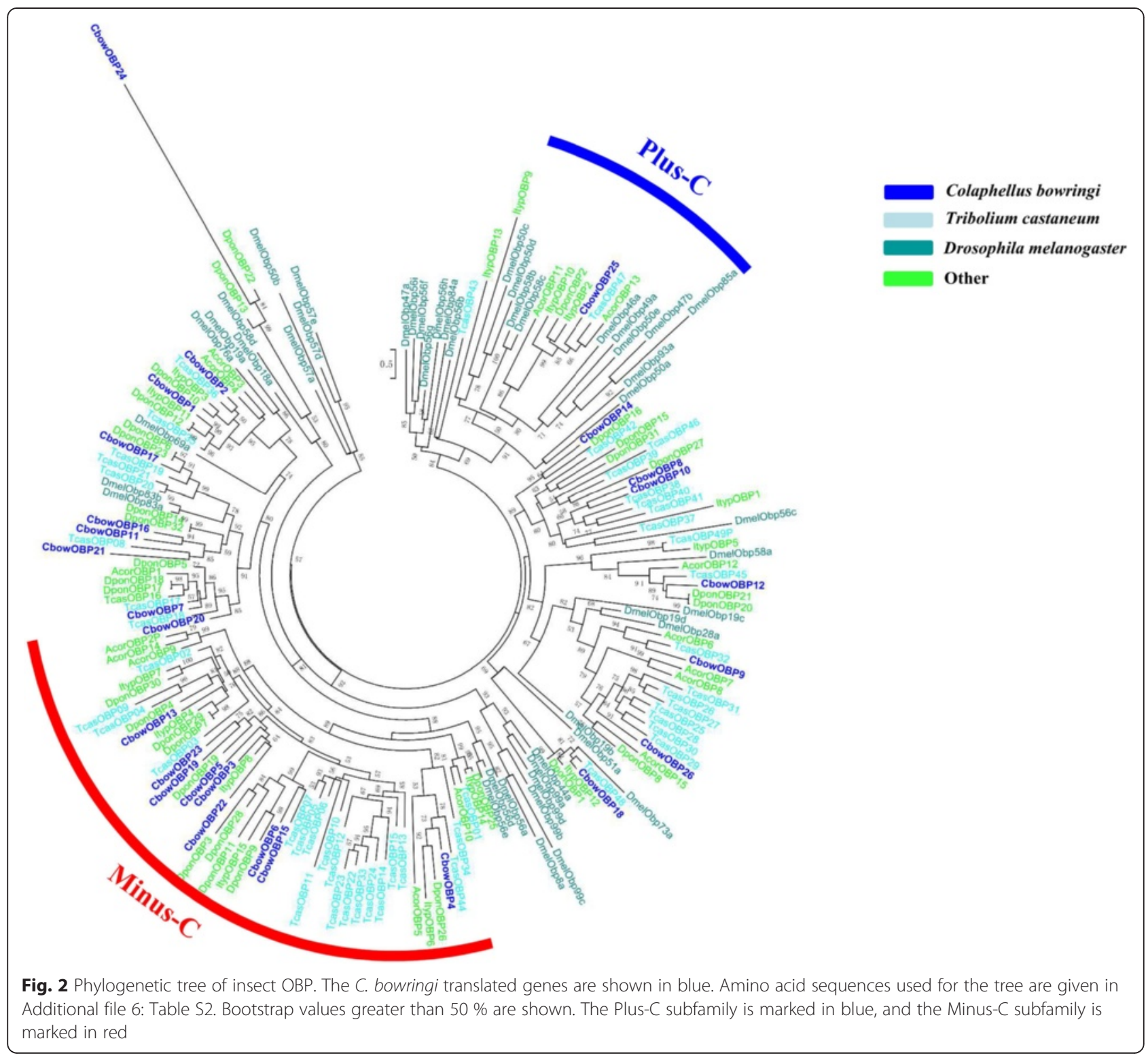

A phylogenetic analysis was conducted using a data set containing the sequences of the 36 ORs longer than 160 amino acids in C. bowringi and 192 ORs from four other coleopteran species (Fig. 4). The OR sequences were clustered into several subgroups according to previous studies. CbowORs were only present within the previously defined coleopteran OR subgroups 1, 2, 3, and 7 as well as the ORco subgroup. We found that 6 CbowORs (CbowOR6, $17,19,22,24$ and 35) and a functionally characterized McarOR20 [43] were clustered in subgroup 1. A total of17 CbowORs (OR3, 4, 7-11, 13-15, 21, 26, 29, 31, 33, 36 and 38 ) and 2 functionally characterized McarORs (OR3 and 5) [43] belong to subgroup 2 (Fig. 4).

The transcriptional profiles of CbowOR genes were characterized using qPCR, and the results revealed that all of the 43 CbowORs displayed predominately antenna linked or otherwise biased expression levels. Although we did not identify apparent sex-specific genes in these $C$. bowringi olfactory receptors, there were six (CbowOR7, 9, 14, 15, 17 and 37) and10 (CbowOR5 10, 12, 22, 25, 29, 30,31, 41 and 42) with significantly higher expression in the male and female antennae, respectively (Fig. 5).

\section{IRs and GRs}

In total, we identified nine IR and ten GR candidates in C. bowringi, which is similar to that reported in other recent antennal transcriptomic studies of coleoptera insects [20, 22] (Fig. 1). Only four of these likely represented a full-length ORF (CbowIR2, 5, 6 and 8a), among which we also found three TMDs. The RPKM results showed that CbowIR6 (RPKM = 74.73) 


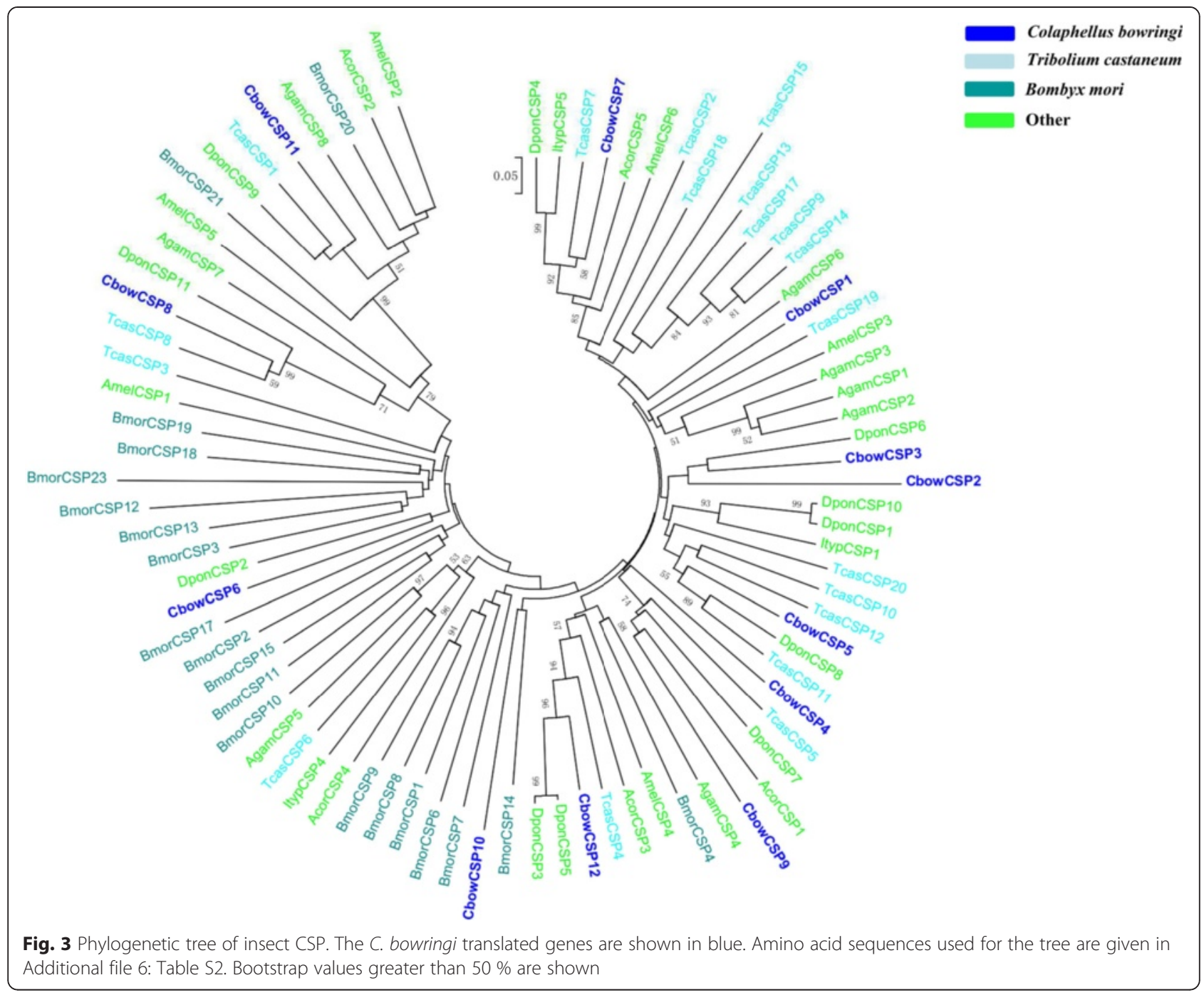

and CbowGR1 (RPKM = 53.07) displayed the highest expression levels (Additional file 4: Table S1). According to the phylogenetic tree of the IRs from D. melanogaster and various coleopterans, we observed all nine CbowIRs were clustered into antennal IRs and IR25a/IR8a clades (Fig. 6).

\section{Discussion}

Compared to dipterans and lepidopterans, the molecular basis of chemoreception in coleopterans is relatively poorly understood. In the current study, we sequenced and analyzed the transcriptome of antennae from C. bowringi. Among the 41,761 unigenes identified, only $45.26 \%$ gene translations shared significant similarity with entries in the NCBI non-redundant (nr) protein database, and only $33.87 \%$ could be annotated to one or more GO term, which is similar to that reported in other coleopteran species [20-22], indicating that a large number of C. bowringi genes are non-coding or homologous to genes that do not have any GO term, or perhaps some are C. bowringi- specific or fast-evolving genes. Importantly, we identified 104 novel chemosensory genes in C. bowringi. Our results not only establish a means to further elucidate the molecular mechanisms of chemosensation, but also provide insight into insect physiology and the development of additional pest control strategies [44].

The total number (104) of chemosensory transcripts identified in C. bowringi is different from what has been reported in D. ponderosae (111) and I. typographus (80), This phenomenon may be due to the evolution of divergent physiological behaviours (such as: herbivory, mating, and oviposition) of different insects during the process of adaptation to various environments [45-47]. Specific environments might lead to divergent evolutionary trajectories of the same ancestral chemosensory genes, resulting in different functional genes among species.

In total, 26 OBPs were identified in the antennal transcriptome of $C$. bowringi. This is close to the number of OBPs in the antennae of $D$. ponderosae (31) and $D$. 


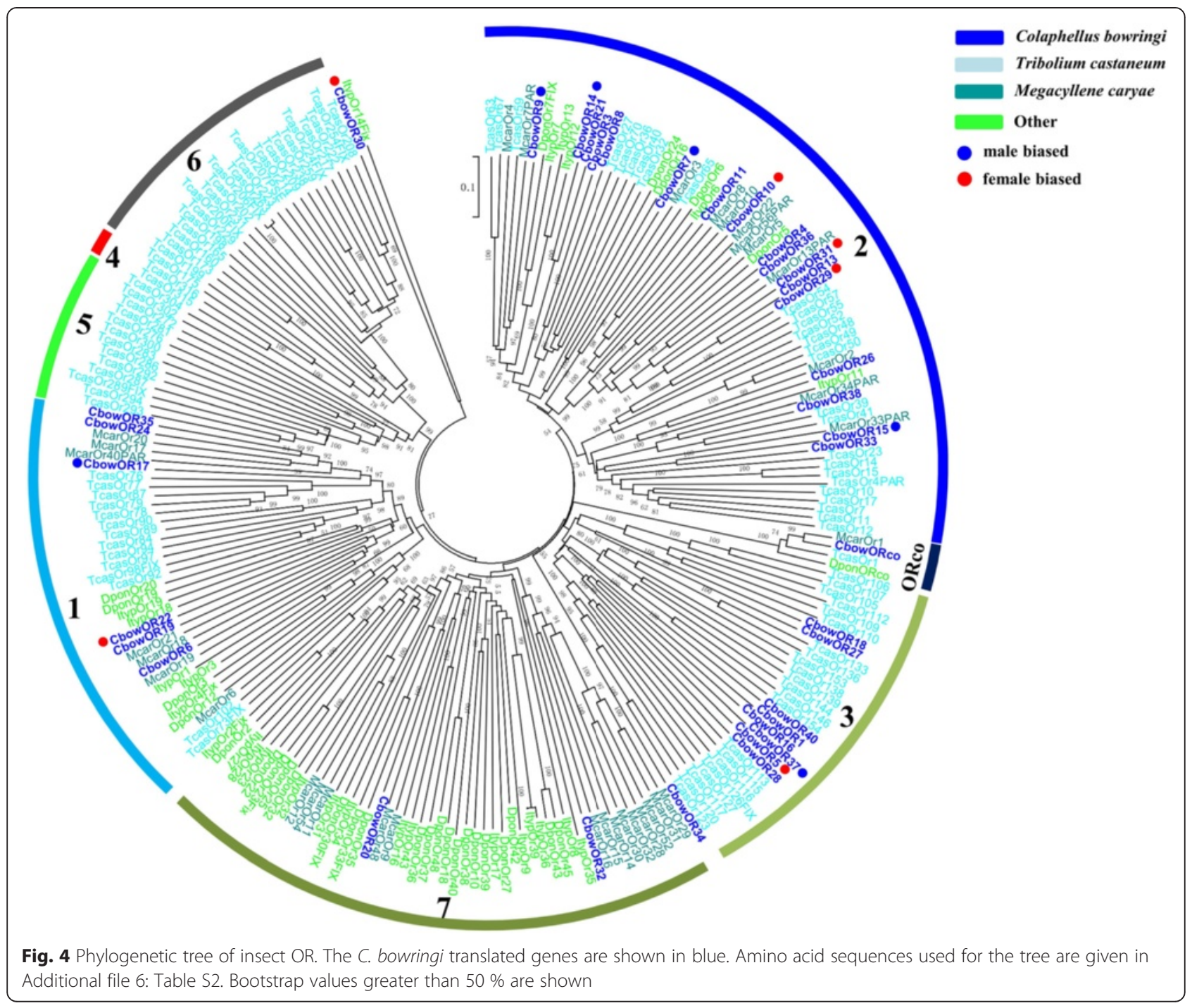

valens (21), however less than in T. castaneum (49). The number of CbowCSPs (12) is similar to $D$. ponderosae (11) while less than T. castaneum (20). Previous studies showed that some insect OBPs and CSPs are expressed primarily or exclusively in non-antennae tissues or in larvae $[23,48-50]$, thus we may not have obtained these types of genes.

Currently, the general mechanism of insect SNMP function is still poorly understood. While DmelSNMP1 is essential for the detection of the pheromone (Z)-11octadecenyl acetate (a volatile male-specific fatty-acidderived pheromone) in D. melanogaster, and it is thought that SNMP acts in concert with odorant receptors to capture pheromone molecules on the surface of olfactory dendrites $[51,52]$. In this study, SNMP transcripts were identified in C. bowringi (4) and were found to be more numerous than those in the $T$. castaneum genome (2). The expression of antennal SNMPs in $C$. bowringi, similar to what was previously reported for other known coleopteran insects, suggests that SNMPs in coleopteran insects may have same role as in $D$. melanogaster.

In comparison with the lepidopterans, although the coleopterans ORs have been focused on in recent years [20-22, 43, 53], species richness and function analyses are still lacking. For this reason, it is necessary to identify additional coleopteran ORs to further elucidate the mechanisms of coleopteran chemosensation. In insects, gene duplications and deletion events may be the major contributors to high levels of diversity in OR genes and variability in gene number among species. Forty-three ORs were first identified in the antennal transcriptome of $C$. bowringi, which is less than the number of ORs in the complete genome of T. castaneum (341). However, it is same as the number of ORs identified in the antennal transcriptome of I. typographus (43) and A. corpulenta 


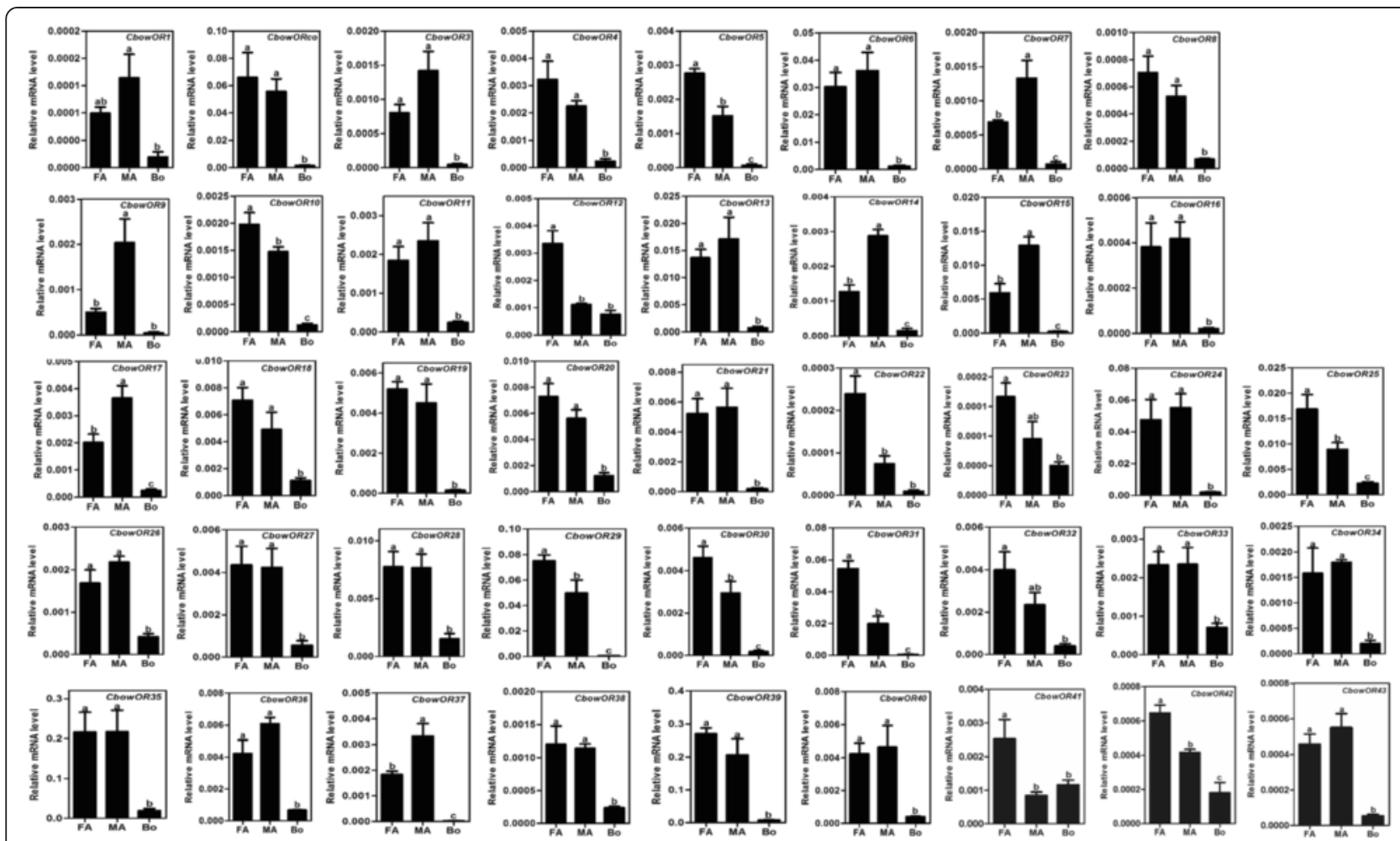

Fig. 5 Relative expression levels of all ORs in adult antennae and whole body, using qPCR. FA, female antennae; MA, male antennae; Bo, whole insect body (without antennae). The relative expression level is indicated as mean $\pm \mathrm{SE}(N=3)$. Different capital letters mean significant difference between tissues $(P<0.05$, ANOVA, LSD)

(43), suggesting we may missed some larvae-biased ORs or those with lower expression levels. Remarkably, similar to what has been observed in T. castaneum, M. caryae, and $A$. corpulenta, a species-specific expansion of ORs (CbowOR1/5/16/28/37/40 and 3/8/14/21) was also found in $C$. bowringi, which may reflect that these distinct species inhabit different ecological niches. $M$. caryae was the first beetle in which the function of the ORs was characterized [43]. For this reason, we are only able to speculate on the possible functions of CbowORs by examining those of the orthologous McarORs. McarOR3 can bind the pheromone component (S)-2-methyl-1-butanol and additional structurally related chemicals using functional analysis in vitro. CbowOR7 displayed a malebiased transcriptional profile characteristic and could be clustered into the same subgroup with McarOR3, indicating that it may have a similar function to McarOR3 as well as other lepidopteran pheromone receptors (PRs) [54-57]. In total, we identified 6 (CbowOR7, 9, 14, 15, 17 and 37) and 10 (CbowOR5, 10, 12, 22, 25, 29, 30, 31, 41 and 42) genes with significantly higher expression levels in male and female antennae, respectively. Based on previous studies of the insect OR functions [57-60], the male-biased CbowORs may be involved in the detection of the sex pheromone or other male-specific behaviours, while female-biased CbowORs may detect odours critical to female behaviour, such as oviposition cues or male-produced courtship pheromones. The sexspecific functions of these CbowORs need to be further investigated in the future.

Furthermore, we identified 9 IRs from the antennal transcriptome assembly in C. bowringi, which is fewer than that in T. castaneum (10) and D. ponderosae (15). This may be due to the possibility that some transcripts were missing from our antennal transcriptome. Like ORco, both IR8a and IR25a were thought to act as coreceptors since they are co-expressed along with other IRs [61]. Sequence alignments and the phylogenetic tree revealed that CbowIR8a and CbowIR6 (25a) belong to the co-expression IR group. To date, multiple GRs have also been identified in different insect species [20, 62-65]. While only ten CbowGRs were found in C. bowringi, this was expected since GRs are primarily expressed in gustatory organs, such as the proboscis and maxillary palps, rather than the antennae [65-67].

\section{Conclusions}

In conclusion, we identified an extensive set of candidate genes that may be related to odorant perception of $C$. bowringi by analyzing transcriptomic sequence data. As 


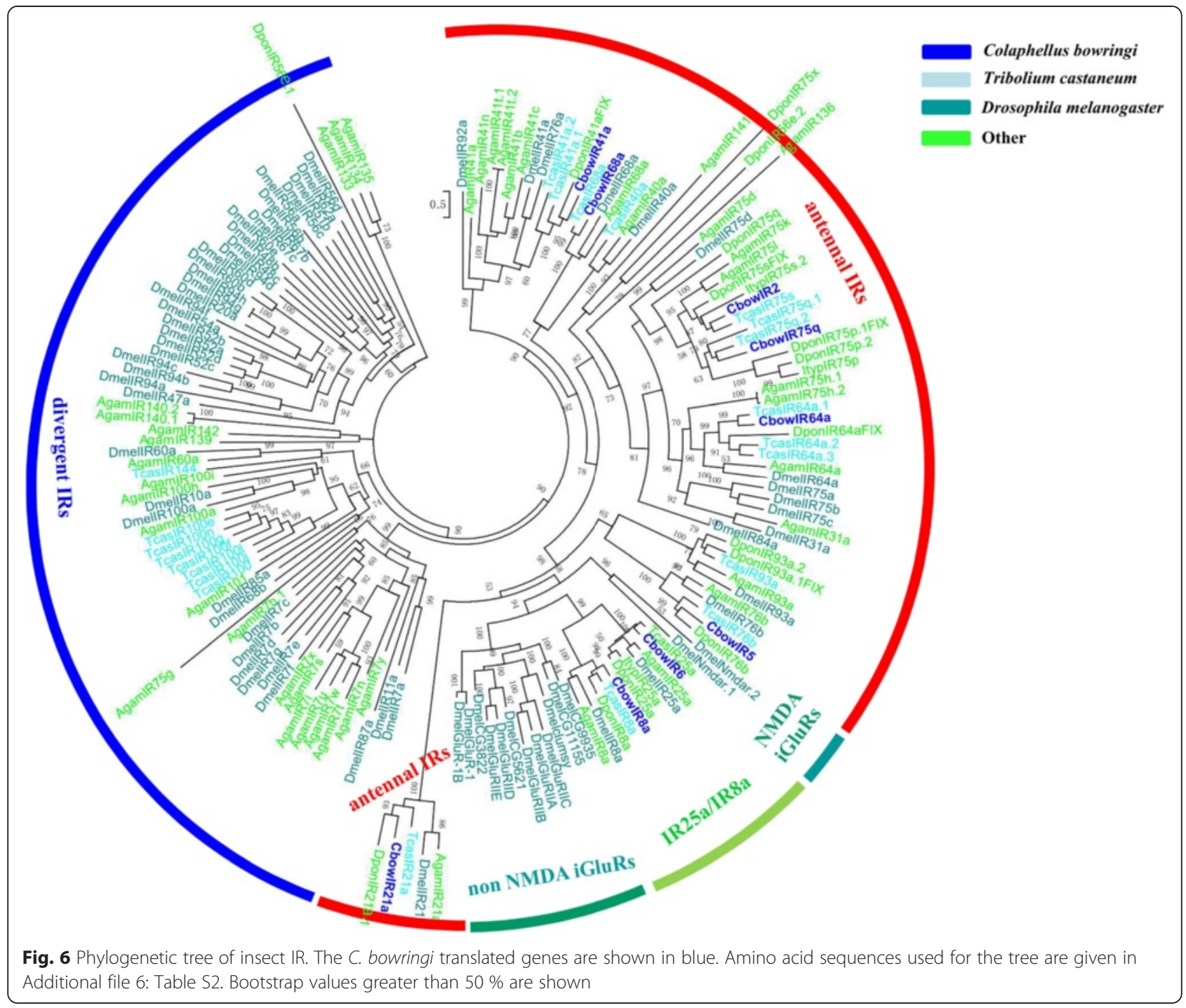

the first step towards understanding gene functions, we conducted a comprehensive and comparative phylogenetic analysis and examined OR gene transcription patterns, some of which were sex-biased. Further analysis is needed to explore the function of these genes using integrated functional studies.

\section{Methods}

\section{Insect rearing and collection}

C. bowringi were collected in April 2015 from a B. campestris field in the Pollution-Free Planting Base of Huaibei City, Huaibei, China. The field studies did not involve endangered or protected species, and no specific permissions were required for these research activities at these locations. Specimens were separated into females and males, and were reared on fresh leaves of $B$. campestris. The rearing conditions were $25^{\circ} \mathrm{C} \pm 1{ }^{\circ} \mathrm{C}$, a $12 \mathrm{~h}$ light : $12 \mathrm{~h}$ dark photoperiod, and $70 \pm 10 \%$ relative humidity
[68]. For transcriptome sequencing, the antennae of 800 adults (400 males and 400 females) were collected. For the expression study of different tissues, 150-200 female antennae (FA), 150-200 male antennae (MA), and 10-15 whole insect body without antennae (Bo) were also collected. All samples were immediately frozen in liquid nitrogen and stored at $-80{ }^{\circ} \mathrm{C}$ until use.

\section{cDNA library construction}

Total RNA was extracted using TRIzol reagent (Invitrogen, Carlsbad, CA, USA), cDNA library construction and Illumina sequencing of the samples were performed at Novogene Bioinformatics Technology Co., Ltd., Beijing, China. The mRNA was purified from $3 \mu \mathrm{g}$ of total RNA using oligo (dT) magnetic beads and fragmented into short sequences in the presence of divalent cations at $94{ }^{\circ} \mathrm{C}$ for $5 \mathrm{~min}$. Then, the first-strand cDNA was generated using random hexamer-primed reverse transcription, followed by 
synthesis of the second-strand cDNA using RNaseH and DNA polymerase I. After the end repair and ligation of adaptors, the products were amplified by PCR and purified using the QIAquick PCR Purification Kit (Qiagen, Valencia, CA, USA) to create a cDNA library, which was assessed on the Agilent Bioanalyzer 2100 system.

\section{Clustering and sequencing}

Clustering of the index-coded samples was performed on a cBot Cluster Generation System using TruSeq PE Cluster Kit v3-cBot-HS (Illumina) according to the manufacturer's instructions. After cluster generation, the libraries were sequenced on an Illumina HiSeq ${ }^{\mathrm{Tm}}$ 2500 platform and paired-end reads were generated.

\section{De novo assembly of short reads and gene annotation}

Clean short reads were obtained by removing those containing an adapter or poly- $\mathrm{N}$ and of low quality from the raw reads. Transcriptome de novo assembly was carried out with the short read assembling program Trinity (r20140413p1) [69, 70] with min_kmer_cov set to two by default and all other parameters also set as default. The resulting sequences were the unigenes. The unigenes larger than $150 \mathrm{bp}$ were first aligned by Blastx to protein databases, including Nr, Swiss-Prot, KEGG, and COG $\left(E\right.$-value $<10^{-5}$ ), retrieving proteins with the highest sequence similarity with the given unigenes along with their protein functional annotations. Then, we used the Blast2GO program [71] to obtain a GO annotation of the unigenes, and GO functional classification with the WEGO software [72].

\section{Expression abundance analysis of the Unigenes}

The expression abundance of these unigenes were calculated based on the reads per kilobase per million mapped reads (RPKM) method [73], using the formula: $\operatorname{RPKM}(\mathrm{A})=(10,00,000 \times \mathrm{C} \times 1000) /(\mathrm{N} \times \mathrm{L})$, where $\mathrm{RPKM}$ (A) is the abundance of gene $\mathrm{A}, \mathrm{C}$ is the number of reads that uniquely aligned to gene $\mathrm{A}, \mathrm{N}$ is the total number of reads that uniquely aligned to all genes, and $\mathrm{L}$ is the number of bases in gene A. The RPKM method was able to eliminate the influence of different gene lengths and sequencing discrepancies in the calculation of expression abundance.

\section{RNA isolation and CDNA synthesis}

Total RNA was extracted with the SV 96 Total RNA Isolation System (Promega, Madison, WI, USA) following the manufacturer's instructions, in which a DNaseI digestion was included to avoid contamination of genomic DNA. RNA quality was checked with a spectrophotometer (NanoDrop $^{\mathrm{TM}} 1000$, Thermo Fisher Scientific, USA). The single-stranded cDNA templates were synthesized from
$1 \mu \mathrm{g}$ of total RNA from the various tissue samples using the PrimeScript ${ }^{\text {sax }}$ RT Master Mix (TaKaRa, Dalian, China).

\section{Sequence analysis}

The open reading frames (ORFs) of the chemosensory genes were predicted using ORF finder (http:// www.ncbi.nlm.nih.gov/gorf/gorf.html). The similarity searches were performed with the NCBI-BLAST network server (http://blast.ncbi.nlm.nih.gov/). Transmembrane domains of both CbowORs and CbowIRs were predicted with the TMHMM Server Version 2.0 (http://www.cbs.dtu.dk/services/TMHMM). Putative Nterminal signal peptides of CbowOBPs and CbowCSPs were predicted by Signal IP 4.1 (http://www.cbs.dtu.dk/ services/SignalP/) [74].

\section{Nomenclature of all genes}

We adopted nomenclature for the CbowORco, CbowIRs and CbowSNMPs that are analogous to those deposited in GenBank (http://www.ncbi.nlm.nih.gov/genbank/). Based on previous studies, CbowOBPs were divided into three groups [3, 4]: Classic OBPs, characterized by 6 cysteine residues at conserved positions; Plus- $\mathrm{C}$ OBPs, which have 4-6 additional cysteines and one characteristic proline; and Minus-C OBPs, which are missing cysteine residues, generally $\mathrm{C} 2$ and $\mathrm{C} 5$. The rest of the chemosensory genes of $C$. bowringi were named based on their order in the antennal transcriptome data.

\section{Phylogenetic analysis}

The phylogenetic trees were reconstructed for the analyses of CbowOBPs, CbowCSPs, CbowSNMP, CbowORs, and CbowIRs, using these genes (the signal peptides of sequences were removed from OBPs and CSPs) as well as the sequences in other insects. The OBP data set contained 26 sequences from C. bowringi and 150 from other insects. The CSP data set contained 12 sequences from $C$. bowringi and 72 from other insects. The SNMP data set contained 4 sequences from $C$. bowringi and 17 from other insects. The OR data set contained 36 sequences from C. bowringi (amino acids $>160$ aa), and 192 from other insects. The IR data set contained 9 sequences from C. bowringi and 108 from other insects. The amino acid sequences of the genes used for phylogenetic tree construction are listed in Additional file 6: Table S2. Amino acid sequences were aligned with ClustalX 1.83 [75] and unrooted trees were constructed with MEGA5.0 [76] using the neighbourjoining method, with Poisson correction of distances (CSP, SNMP, and OR) and FastTree 2.1.7 [77] using maximum-likelihood method (OBP and IR). The species phylogenetic tree was constructed based on the alignment result of cytochrome oxidase subunit I 
(COI) genes, from different species ( $T$. castaneum: KJ003352.1, I. typographus: KF846151.1, D. ponderosae: JQ308497.1, D. valens: EU404100.1 and A. corpulenta: the reference [19]) using MEGA5.0.

\section{Quantitative real time-PCR validation}

The expression profiles of 43 OR genes were analyzed using quantitative real time-PCR (qPCR) experiments. The qPCR was performed on an ABI 7300 (Applied Biosystems, Foster City, CA, USA) using a mixture of $10 \mu \mathrm{l} 2 \times$ TransStart Top Green qPCR SuperMix (TransGen Biotech, Beijing, China), $0.4 \mu \mathrm{l}$ of each primer $(10 \mu \mathrm{M}), 2.5 \mathrm{ng}$ of sample cDNA, and $6.8 \mu \mathrm{l}$ sterilized ultrapure $\mathrm{H}_{2} \mathrm{O}$. The reaction programs were $30 \mathrm{~s}$ at $94{ }^{\circ} \mathrm{C}, 40$ cycles of $94{ }^{\circ} \mathrm{C}$ for $5 \mathrm{~s}$ and $60{ }^{\circ} \mathrm{C}$ for $31 \mathrm{~s}$. This was followed by the measurement of fluorescence during $55-95{ }^{\circ} \mathrm{C}$ melting curve in order to detect a single gene-specific peak and to check the absence of primer dimer peaks. A single and discrete peak was detected for all primers tested. Negative controls were nontemplate reactions (replacing cDNA with $\mathrm{H}_{2} \mathrm{O}$ ). The results were analyzed using the ABI 7300 analysis software SDS 1.4. The qPCR primers (Additional file 7: Table S3) were designed using Beacon Designer 7.9 (PREMIER Biosoft International, CA, USA).

According to a previous study [68], expression levels of these genes were calculated relative to the two most stable reference genes CbowEF1 $\alpha$ and CbowACT1 using the Q-Gene method in Microsoft Excel-based software of Visual Basic [78, 79]. For each sample, three biological replications were performed with each biological replication measured in three technique replications.

\section{Statistical analysis}

Data (mean \pm SE) form various samples were subjected to a one-way nested analysis of variance (ANOVA) followed by the least significant difference test (LSD) for mean comparison using SPSS Statistics 17.0 (SPSS Inc., Chicago, IL, USA).

\section{Supporting information}

All the Illumina sequencing data are available from the SRA database (accession number: SRX1309381), and all of the chemosensory genes of Colaphellus bowringi were submitted to the GenBank (accession numbers: KT381483 KT381577 and KT884510 - KT884516).

\section{Additional files}

Additional file 1: Figure S1. Distribution of unigene size in the C. bowringi transcriptome assembly. (TIF $190 \mathrm{~kb}$ )

Additional file 2: Figure S2. Percentage of homologous hits of the $C$. bowringi transcripts to other insect species. The C. bowringi transcripts were searched by Blastx against the non-redundancy protein database with a cutoff E-value $10^{-5}$. Species that have more than $1 \%$ matching hits to the C. bowringi transcripts are shown. (TIF $221 \mathrm{~kb}$ )

Additional file 3: Figure S3. Gene ontology (GO) classification of the $C$. bowringi transcripts with Blast2GO program. (TIF $1678 \mathrm{~kb}$ )

Additional file 4: Table S1. The Reads Per Kilobase per Million mapped reads (RPKM) values of CbowOBPs, CSPs, SNMPs, IRs and GRs. (XLSX $10 \mathrm{~kb}$ )

Additional file 5: Figure S4. Phylogenetic tree of insect SNMP. The $C$. bowringi translated genes are shown in blue. Amino acid sequences used for the tree are given in Additional file 6: Table S2. Values at the nodes are results of bootstrap with 1000 replicates and values greater than $50 \%$ are shown. (TIF $141 \mathrm{~kb}$ )

Additional file 6: Table S2. Amino acid sequences of C. bowringi and other insect used in phylogenetic analyses. (PDF $814 \mathrm{~kb}$ )

Additional file 7: Table S3. Primers used for qPCR. (XLS 29 kb)

\section{Abbreviations}

RNA-seq: High-throughput mRNA sequencing; RPKM: Reads per kilobase per million mapped reads; GO: Gene ontology; KEGG: Kyoto encyclopedia of genes and genomes; COG: Clusters of orthologous groups; OR: Odorant receptor; GR: Gustatory receptor; IR: Ionotropic receptor; OBP: Odorant-binding protein; CSP: Chemosensory protein; SNMP: Sensory neuron membrane protein; ORF: Open reading frame; TMD: Transmembrane domain; PCR: Polymerase chain reaction; qPCR: Quantitative real time RT-PCR; CDNA: Complementary DNA; ANOVA: Analysis of variance; SE: Standard error.

\section{Competing interests}

The authors declare no conflict of interests.

\section{Authors' contributions}

$X M L$ and YNZ conceived and designed the experimental plan. ZQW, YW and $G C$ preformed the experiments. XML, XYZ, PH, LS, DGD and YNZ analyzed and interpreted the sequence data. YNZ drafted the manuscript. All authors read and approved the final manuscript.

\section{Acknowledgements}

We thank Bachelor students Wei-Wei Zhou, Tian Tian, Xiao-Tong Zhu and Xiao-Xue Xu (Huaibei Normal University, China) for help collecting insects. We are grateful to Dr. Xiao Li (Shandong Peanut Research Institute, China) for providing the $\mathrm{CO}$ sequence of $\mathrm{A}$. corpulenta. This work was supported by grants from the National Natural Science Foundation (NO. 31240075 and 31501647) of China, Natural Science Fund of Education Department of Anhui province (NO. KJ2013A233), and Doctor Scientific Research Foundation of Huaibei Normal University, China (NO. 1500969).

\section{Author details}

${ }^{1}$ College of Life Sciences, Huaibei Normal University, Huaibei 235000, China. ${ }^{2}$ State Key Laboratory Breeding Base of Green Pesticide and Agricultural Bioengineering, Key Laboratory of Green Pesticide and Agricultural Bioengineering, Ministry of Education, Guizhou University, Guiyang 550025, China. ${ }^{3}$ Tea Research Institute, Chinese Academy of Agricultural Sciences, Hangzhou 310008, China.

Received: 13 August 2015 Accepted: 23 November 2015

Published online: 02 December 2015

\section{References}

1. Leal WS. Odorant reception in insects: roles of receptors, binding proteins, and degrading enzymes. Annu Rev Entomol. 2013;58(1):373-91. doi:10.1146/annurev-ento-120811-153635.

2. Vogt RG. Biochemical diversity of odor detection:OBPs, ODEs and SNMPs. In: Blomquist GJ, Vogt RG, editors. Insect pheromone biochemistry and molecular biology. California: Elsevier; 2003. p. 397-451.

3. Zhou JJ. Odorant-binding proteins in insects. Vitam Horm. 2010;83:241-72. doi:10.1016/S0083-6729(10)83010-9.

4. Xu YL, He P, Zhang L, Fang SQ, Dong SL, Zhang YJ, et al. Large-scale identification of odorant-binding proteins and chemosensory proteins from 
expressed sequence tags in insects. BMC Genomics. 2009;10(25):632. doi:10.1186/1471-2164-10-632.

5. Pelosi P, Zhou JJ, Ban LP, Calvello M. Soluble proteins in insect chemical communication. Cell Mol Life Sci. 2006;63(14):1658-76. doi:10.1007/s00018-005-5607-0.

6. Pelosi P, Calvello M, Ban L. Diversity of odorant-binding proteins and chemosensory proteins in insects. Chem Senses. 2005;30 Suppl 1:i291-2. doi:10.1093/chemse/bjh229.

7. Zhang J, Walker WB, Wang G. Pheromone reception in moths: from molecules to behaviors. Prog Mol Biol Transl Sci. 2015;130:109-28. doi:10.1016/bs.pmbts.2014.11.005.

8. Crasto CJ. Olfactory Receptors. In: Walker JM, editor. Methods in molecular biologyTM. New York: Springer; 2013.

9. Robertson HM, Warr CG, Carlson JR. Molecular evolution of the insect chemoreceptor gene superfamily in Drosophila melanogaster. Proc Natl Acad Sci U S A. 2003;100 Suppl 2:14537-42. doi:10.1073/pnas.23358471002335847100.

10. Sanchez-Gracia A, Vieira FG, Rozas J. Molecular evolution of the major chemosensory gene families in insects. Heredity (Edinb). 2009;103(3):208-16. doi:10.1038/hdy.2009.55.

11. Rogers ME, Sun M, Lerner MR, Vogt RG. Snmp-1, a novel membrane protein of olfactory neurons of the silk moth Antheraea polyphemus with homology to the CD36 family of membrane proteins. J Biol Chem. 1997;272(23):14792-9.

12. Vogt RG, Miller NE, Litvack R, Fandino RA, Sparks J, Staples J, et al. The insect SNMP gene family. Insect Biochem Mol Biol. 2009;39(7):448-56. doi:10.1016/j.ibmb.2009.03.007.

13. Tunstall NE, Warr CG. Chemical communication in insects: the peripheral odour coding system of Drosophila melanogaster. Adv Exp Med Biol. 2012; 739:59-77. doi:10.1007/978-1-4614-1704-0_4.

14. Benton R, Vannice KS, Gomez-Diaz C, Vosshall LB. Variant ionotropic glutamate receptors as chemosensory receptors in Drosophila. Cell. 2009; 136(1):149-62. doi:10.1016/j.cell.2008.12.001.

15. Croset V, Rytz R, Cummins SF, Budd A, Brawand D, Kaessmann H, et al. Ancient protostome origin of chemosensory ionotropic glutamate receptors and the evolution of insect taste and olfaction. PLoS Genet. 2010;6(8): e1001064. doi:10.1371/journal.pgen.1001064.

16. McKenna MP, Hekmat-Scafe DS, Gaines P, Carlson JR. Putative Drosophila pheromone-binding proteins expressed in a subregion of the olfactory system. J Biol Chem. 1994:269(23):16340-7.

17. Picimbon JF, Gadenne C. Evolution of noctuid pheromone binding proteins: identification of PBP in the black cutworm moth, Agrotis ipsilon. Insect Biochem Mol Biol. 2002;32(8):839-46.

18. Xiu WM, Zhou YZ, Dong SL. Molecular characterization and expression pattern of two pheromone-binding proteins from Spodoptera litura (Fabricius). J Chem Ecol. 2008;34(4):487-98. doi:10.1007/s10886-008-9452-0.

19. Calvello M, Brandazza A, Navarrini A, Dani FR, Turillazzi S, Felicioli A, et al. Expression of odorant-binding proteins and chemosensory proteins in some Hymenoptera. Insect Biochem Mol Biol. 2005;35(4):297-307. doi:10.1016/j.ibmb.2005.01.002.

20. Andersson MN, Grosse-Wilde E, Keeling Cl, Bengtsson JM, Yuen MM, Li M, et al. Antennal transcriptome analysis of the chemosensory gene families in the tree killing bark beetles, Ips typographus and Dendroctonus ponderosae (Coleoptera: Curculionidae: Scolytinae). BMC Genomics. 2013;14:198. doi:10.1186/1471-2164-14-198.

21. Gu XC, Zhang YN, Kang K, Dong SL, Zhang LW. Antennal transcriptome analysis of odorant reception genes in the Red Turpentine Beetle (RTB), Dendroctonus valens. PLoS One. 2015;10(5):e0125159. doi:10.1371/journal.pone.0125159.

22. Li X, Ju Q, Jie W, Li F, Jiang X, Hu J, et al. Chemosensory gene families in adult antennae of Anomala corpulenta Motschulsky (Coleoptera: Scarabaeidae: Rutelinae). PLoS ONE. 2015;10(4):e0121504. doi:10.1371/journal.pone.0121504.

23. Zhang YN, Jin JY, Jin R, Xia YH, Zhou JJ, Deng JY, et al. Differential expression patterns in chemosensory and non-chemosensory tissues of putative chemosensory genes identified by transcriptome analysis of insect pest the purple stem borer Sesamia inferens (Walker). PLoS ONE. 2013;8(7): e69715. doi:10.1371/journal.pone.0069715.

24. Liu Y, Gu S, Zhang Y, Guo Y, Wang G. Candidate olfaction genes identified within the Helicoverpa armigera antennal transcriptome. PLoS ONE. 2012; 7(10):e48260. doi:10.1371/journal.pone.0048260.
25. Gong DP, Zhang HJ, Zhao P, Xia QY, Xiang ZH. The odorant binding protein gene family from the genome of silkworm, Bombyx mori. BMC Genomics. 2009;10:332. doi:10.1186/1471-2164-10-332.

26. Pelletier J, Leal WS. Characterization of olfactory genes in the antennae of the Southern house mosquito, Culex quinquefasciatus. J Insect Physiol. 2011; 57(7):915-29. doi:10.1016/j.jinsphys.2011.04.003.

27. Gu SH, Wang SP, Zhang XY, Wu KM, Guo YY, Zhou JJ, et al. Identification and tissue distribution of odorant binding protein genes in the lucerne plant bug Adelphocoris lineolatus (Goeze). Insect Biochem Mol Biol. 2011; 41(4):254-63. doi:10.1016/j.ibmb.2011.01.002.

28. Robertson HM, Wanner KW. The chemoreceptor superfamily in the honey bee, Apis mellifera: expansion of the odorant, but not gustatory, receptor family. Genome Res. 2006;16(11):1395-403. doi:10.1101/gr.5057506.

29. Olivier V, Monsempes C, Francois MC, Poivet E, Jacquin-Joly E. Candidate chemosensory ionotropic receptors in a Lepidoptera. Insect Mol Biol. 2011; 20(2):189-99. doi:10.1111/j.1365-2583.2010.01057.x.

30. Krieger J, Grosse-Wilde E, Gohl T, Dewer YM, Raming K, Breer H. Genes encoding candidate pheromone receptors in a moth (Heliothis virescens). Proc Natl Acad Sci U S A. 2004;101(32):11845-50. doi:10.1073/pnas. 04030521010403052101.

31. Xue F, Li A, Zhu X, Gui A, Jiang P, Liu X. Diversity in life history of the leaf beetle, Colaphellus bowringi. Baly Acta Entom Sin. 2002;45(4):494-8.

32. Wang XP. Diapause induction and post-diapause life-history traits in the cabbage beetle, Colaphellus bowringi (Coleoptera: Chrysomelidae) Phd thesis, Hunan Agricultural University. 2004.

33. Liu XP, He HM, Kuang XJ, Xue FS. Mating behavior of the cabbage beetle Colaphellus bowringi Baly (Coleoptera: Chrysomelidae). Insect Sci. 2010;17(1):61-6

34. Liu XP, He HM, Kuang XJ, Xue FS. A comparison of female fitness between monogamy and polyandry in the cabbage beetle, Colaphellus bowringi. Anim Behav. 2010;79(6):1391-5.

35. Liu XP, He HM, Xue FS. The effect of mating frequency and mating pattern on female reproductive fitness in cabbage beetle, Colaphellus bowringi. Entomol Exp Appl. 2013;146(3):379-85.

36. Liu XP, Xu J, He HM, Xue FS. Male age affects female mate preference and reproductive performance in the cabbage beetle, Colaphellus bowringi. J Insect Behav. 2011;24(2):83-93.

37. Liu XP, He HM, Xue FS. The influence of female age on male mating preference and reproductive success in cabbage beetle, Colaphellus bowringi. Insect Sci. 2014;21(4):515-22.

38. Gao Y, Jurat-Fuentes JL, Oppert B, Fabrick JA, Liu C, Gao J, et al. Increased toxicity of Bacillus thuringiensis Cry3Aa against Crioceris quatuordecimpunctata, Phaedon brassicae and Colaphellus bowringi by a Tenebrio molitor cadherin fragment. Pest Manag Sci. 2011;67(9):1076-81. doi:10.1002/ps.2149.

39. Shu C, Su H, Zhang J, He K, Huang D, Song F. Characterization of cry9Da4, cry9Eb2, and cry9Ee1 genes from Bacillus thuringiensis strain T03B001. Appl Microbiol Biotechnol. 2013;97(22):9705-13. doi:10.1007/s00253-013-4781-5.

40. Hull JJ, Perera OP, Snodgrass GL. Cloning and expression profiling of odorant-binding proteins in the tarnished plant bug, Lygus lineolaris. Insect Mol Biol. 2014;23(1):78-97. doi:10.1111/imb.12064.

41. Zhou JJ, Huang W, Zhang GA, Pickett JA, Field LM. "Plus-C" odorant-binding protein genes in two Drosophila species and the malaria mosquito Anopheles gambiae. Gene. 2004;327(1):117-29. doi:10.1016/.j.gene.2003.11.007.

42. Spinelli S, Lagarde A, lovinella I, Legrand $P$, Tegoni M, Pelosi $P$, et al. Crystal structure of Apis mellifera OBP14, a C-minus odorant-binding protein, and its complexes with odorant molecules. Insect Biochem Mol Biol. 2012;42(1):41-50. doi:10.1016/j.ibmb.2011.10.005.

43. Mitchell RF, Hughes DT, Luetje CW, Millar JG, Soriano-Agaton F, Hanks LM, et al. Sequencing and characterizing odorant receptors of the cerambycid beetle Megacyllene caryae. Insect Biochem Mol Biol. 2012;42(7):499-505. doi:10.1016/j.ibmb.2012.03.007.

44. Zhou JJ, Field LM, He XL. Insect odorant-binding proteins: Do they offer an alternative pest control strategy? Outlooks Pest Manag. 2010;21(1):31-4.

45. Goldman-Huertas B, Mitchell RF, Lapoint RT, Faucher CP, Hildebrand JG, Whiteman NK. Evolution of herbivory in Drosophilidae linked to loss of behaviors, antennal responses, odorant receptors, and ancestral diet. Proc Natl Acad Sci U S A. 2015;112(10):3026-31. doi:10.1073/pnas.1424656112.

46. Zhou X, Slone JD, Rokas A, Berger SL, Liebig J, Ray A, et al. Phylogenetic and transcriptomic analysis of chemosensory receptors in 
a pair of divergent ant species reveals sex-specific signatures of odor coding. PLoS Genet. 2012;8(8):e1002930. doi:10.1371/journal.pgen.1002930.

47. Lavagnino N, Serra F, Arbiza L, Dopazo H, Hasson E. Evolutionary enomics of genes involved in olfactory behavior in the Drosophila melanogaster species group. Evol Bioinform Online. 2012;8:89-104. doi:10.4137/EBO.S8484.

48. Poivet E, Gallot A, Montagne N, Glaser N, Legeai F, Jacquin-Joly E. A comparison of the olfactory gene repertoires of adults and larvae in the noctuid moth Spodoptera littoralis. PLoS ONE. 2013;8(4):e60263. doi:10.1371/journal.pone.0060263.

49. Zhou SS, Sun Z, Ma W, Chen W, Wang MQ. De novo analysis of the Nilaparvata lugens (Stål) antenna transcriptome and expression patterns of olfactory genes. Comp Biochem Physiol Part D Genomics Proteomics. 2014;9:31-9. doi:10.1016/j.cbd.2013.12.002.

50. Dippel S, Oberhofer G, Kahnt J, Gerischer L, Opitz L, Schachtner J, et al. Tissue-specific transcriptomics, chromosomal localization, and phylogeny of chemosensory and odorant binding proteins from the red flour beetle Tribolium castaneum reveal subgroup specificities for olfaction or more general functions. BMC Genomics. 2014;15(1):1141. doi:10.1186/1471-2164-15-1141.

51. Benton R, Vannice KS, Vosshall LB. An essential role for a CD36-related receptor in pheromone detection in Drosophila. Nature. 2007:450(7167): 289-93. doi:10.1038/nature06328.

52. Jin $\mathrm{X}, \mathrm{Ha}$ TS, Smith DP. SNMP is a signaling component required for pheromone sensitivity in Drosophila. Proc Natl Acad Sci U S A. 2008;105(31): 10996-1001. doi:10.1073/pnas.0803309105.

53. Tribolium Genome Sequencing C, Richards S, Gibbs RA, Weinstock GM, Brown SJ, Denell $\mathrm{R}$, et al. The genome of the model beetle and pest Tribolium castaneum. Nature. 2008:452(7190):949-55. doi:10.1038/nature06784.

54. Jiang XJ, Guo H, Di C, Yu S, Zhu L, Huang LQ, et al. Sequence similarity and functional comparisons of pheromone receptor orthologs in two closely related Helicoverpa species. Insect Biochem Mol Biol. 2014;48:63-74. doi:10.1016/j.ibmb.2014.02.010.

55. Mitsuno H, Sakurai T, Murai M, Yasuda T, Kugimiya S, Ozawa R, et al. Identification of receptors of main sex-pheromone components of three Lepidopteran species. Eur J Neurosci. 2008;28(5):893-902. doi:10.1111/j.1460-9568.2008.06429.x.

56. Zhang J, Yan S, Liu Y, Jacquin-Joly E, Dong S, Wang G. Identification and functional characterization of sex pheromone receptors in the common cutworm (Spodoptera litura). Chem Senses. 2015;40(1):7-16. doi:10.1093/chemse/bju052bju052.

57. Zhang YN, Zhang J, Yan SW, Chang HT, Liu Y, Wang GR, et al. Functional characterization of sex pheromone receptors in the purple stem borer, Sesamia inferens (Walker). Insect Mol Biol. 2014;23(5):611-20. doi:10.1111/imb.12109.

58. Steinwender B, Thrimawithana AH, Crowhurst RN, Newcomb RD. Pheromone receptor evolution in the cryptic leafroller species, Ctenopseustis obliquana and C. herana. J Mol Evol. 2015;80(1):42-56. doi:10.1007/s00239-014-9650-z

59. Pelletier J, Hughes DT, Luetje CW, Leal WS. An odorant receptor from the southern house mosquito Culex pipiens quinquefasciatus sensitive to oviposition attractants. PLoS ONE. 2010;5(4):e10090. doi:10.1371/journal.pone.0010090.

60. Anderson AR, Wanner KW, Trowell SC, Warr CG, Jaquin-Joly E, Zagatti P, et al. Molecular basis of female-specific odorant responses in Bombyx mori. Insect Biochem Mol Biol. 2009;39(3):189-97. doi:10.1016/j.ibmb.2008.11.002.

61. Abuin L, Bargeton B, Ulbrich MH, Isacoff EY, Kellenberger S, Benton R. Functional architecture of olfactory ionotropic glutamate receptors. Neuron. 2011;69(1):44-60. doi:10.1016/j.neuron.2010.11.042.

62. Liu NY, Xu W, Papanicolaou A, Dong SL, Anderson A. Identification and characterization of three chemosensory receptor families in the cotton bollworm Helicoverpa armigera. BMC Genomics. 2014;15:597. doi:10.1186/1471-2164-15-5971471-2164-15-597.

63. Xu W, Papanicolaou A, Liu NY, Dong SL, Anderson A. Chemosensory receptor genes in the Oriental tobacco budworm Helicoverpa assulta. Insect Mol Biol. 2015;24(2):253-63. doi:10.1111/imb.12153.

64. Leitch O, Papanicolaou A, Lennard C, Kirkbride KP, Anderson A. Chemosensory genes identified in the antennal transcriptome of the blowfly Calliphora stygia. BMC Genomics. 2015;16:255. doi:10.1186/s12864-015-1466-810.1186/s12864-015-1466-8.

65. Sparks JT, Vinyard BT, Dickens JC. Gustatory receptor expression in the labella and tarsi of Aedes aegypti. Insect Biochem Mol Biol. 2013;43(12): 1161-71. doi:10.1016/j.jbmb.2013.10.005.

66. Clyne PJ, Warr CG, Carlson JR. Candidate taste receptors in Drosophila. Science. 2000;287(5459):1830-4.

67. Obiero GF, Mireji PO, Nyanjom SR, Christoffels A, Robertson HM, Masiga DK. Odorant and gustatory receptors in the tsetse fly Glossina morsitans morsitans. PLoS Negl Trop Dis. 2014;8(4):e2663. doi:10.1371/journal.pntd. 0002663.

68. Tan QQ, Zhu L, Li Y, Liu W, Ma WH, Lei CL, et al. A de novo transcriptome and valid reference genes for quantitative real-time PCR in Colaphellus bowringi. PLOS ONE. 2015;10(2):e0118693. doi:10.1371/journal.pone.0118693.

69. Grabherr MG, Haas BJ, Yassour M, Levin JZ, Thompson DA, Amit I, et al. Full-length transcriptome assembly from RNA-Seq data without a reference genome. Nat Biotechnol. 2011;29(7):644-52. doi:10.1038/nbt.1883.

70. Li R, Zhu H, Ruan J, Qian W, Fang X, Shi Z, et al. De novo assembly of human genomes with massively parallel short read sequencing. Genome Res. 2010;20(2):265-72. doi:10.1101/gr.097261.109.

71. Conesa A, Gotz S, Garcia-Gomez JM, Terol J, Talon M, Robles M. Blast2GO: a universal tool for annotation, visualization and analysis in functional genomics research. Bioinformatics. 2005;21(18):3674-6. doi:10.1093/bioinformatics/bti610

72. Ye J, Fang L, Zheng H, Zhang Y, Chen J, Zhang Z, et al. WEGO: a web tool for plotting GO annotations. Nucleic Acids Res. 2006;34(Web Server issue): W293-7. doi:10.1093/nar/gkl031.

73. Mortazavi A, Williams BA, McCue K, Schaeffer L, Wold B. Mapping and quantifying mammalian transcriptomes by RNA-Seq. Nat Methods. 2008;5(7): 621-8. doi:10.1038/nmeth.1226.

74. Petersen TN, Brunak S, von Heijne G, Nielsen H. SignalP 4.0: discriminating signal peptides from transmembrane regions. Nat Methods. 2011;8(10):785-6. doi:10.1038/nmeth.1701nmeth.1701.

75. Larkin MA, Blackshields G, Brown NP, Chenna R, McGettigan PA, McWilliam $\mathrm{H}$, et al. Clustal W and Clustal X version 2.0. Bioinformatics. 2007;23(21): 2947-8. doi:10.1093/bioinformatics/btm404.

76. Tamura K, Peterson D, Peterson N, Stecher G, Nei M, Kumar S. MEGA5 molecular evolutionary genetics analysis using maximum likelihood, evolutionary distance, and maximum parsimony methods. Mol Biol Evol. 2011;28(10):2731-9.

77. Price MN, Dehal PS, Arkin AP. FastTree 2-approximately maximumlikelihood trees for large alignments. PLoS ONE. 2010;5(3):e9490. doi:10.1371/journal.pone.0009490.

78. Simon P. Q-Gene: processing quantitative real-time RT-PCR data. Bioinformatics. 2003;19(11):1439-40

79. Muller PY, Janovjak H, Miserez AR, Dobbie Z. Processing of gene expression data generated by quantitative real-time RT-PCR. Biotechniques. 2002;32(6): $1372-4,6,8-9$.

\section{Submit your next manuscript to BioMed Central and we will help you at every step:}

- We accept pre-submission inquiries

- Our selector tool helps you to find the most relevant journal

- We provide round the clock customer support

- Convenient online submission

- Thorough peer review

- Inclusion in PubMed and all major indexing services

- Maximum visibility for your research

Submit your manuscript at www.biomedcentral.com/submit
C) Biomed Central 